\title{
Electrochemical sensor based on molecularly imprinted film for high sensitivity detection of clenbuterol prepared using sol-gel method
}

\author{
Li Liu ${ }^{1}$, Chenghong Long ${ }^{1}$, Shenghui Wei, ${ }^{2, *}, Y u S^{3} n^{3}$ \\ ${ }^{1}$ Sports Department, Chongqing Jiaotong University, Chongqing, 400074, China \\ ${ }^{2}$ College of Physical and Health Science, Chongqing Normal University, Chongqing, 401331, China \\ ${ }^{3}$ Basic Science Department, Wuchang Shouyi University, Wuhan Hubei, 430064, China \\ *E-mail: weishenghui@vtcuni.com
}

doi: $10.20964 / 2021.04 .27$

Received: 15 December 2020 / Accepted: 24 January 2021 / Published: 28 February 2021

The determination of clenbuterol is crucial for food safety and sport science. In this work, we use tetraethyl orthosilicate and (3-aminopropyl)triethoxysilane as cross-linking agents and functional monomers for the electrodeposition of $\mathrm{SiO}_{2}$ films with the addition of clenbuterol. After the elution process, the prepared electrode can be used for the sensitive determination of clenbuterol due to the molecular imprinting effect. Under optimum conditions, results show that the current of clenbuterol decreases linearly in the range of $2 \mu \mathrm{M}$ to $0.1 \mathrm{mM}$, and the detection limit is $31 \mathrm{nM}$. The proposed electrochemical sensor also exhibits excellent stability and reproducibility, showing its high potential for use in sensing clenbuterol in food samples.

Keywords: Clenbuterol; Sol-gel; $\mathrm{SiO}_{2}$; Electrodeposition; Molecular imprinting

\section{$\underline{\text { FULL TEXT }}$}

(C) 2021 The Authors. Published by ESG (www.electrochemsci.org). This article is an open access article distributed under the terms and conditions of the Creative Commons Attribution license (http://creativecommons.org/licenses/by/4.0/). 